\title{
TREND ANALYSIS OF FIRST YEAR STUDENT EXPERIENCE IN UNIVERSITY
}

\author{
L. L. Lekena
}

Directorate of Quality Promotion

Tshwane University of Technology

Pretoria, South Africa

e-mail: Lekenall@tut.ac.za

\author{
A. Bayaga \\ Department of Mathematics, Science \& Technology Education \\ University of Zululand \\ KwaDlangezwa, South Africa \\ e-mail: BayagaA@unizulu.ac.za,
}

\section{ABSTRACT}

Using the theoretical framework of Tinto (2013), the first objective of the current research was to establish first year students' experience in the first few weeks of their studies in university, and the second objective addressed some of the problems they faced within those first few weeks. Based on the research objectives, data was collected using a questionnaire data. The total number of participants in the survey was 4020 . This represented 27 per cent (4 020 out of 15217 ) of all University of the Mega Don (pseudonym) first year students registered in 2014.

Findings of the study revealed that $34(0.9 \%)$ of the surveyed students reported that they have disabilities. Of all these students with disability, the majority (327 out of 338 (96.7\%) are not registered with the disability office. Over 50 per cent of students, typically those from low-income or deprived circumstances, dropout due to financial struggles to carry the direct and indirect costs of university attendance. Some of dropout as the financial circumstances depreciate. Findings further indicated that late registration and other reasons were the cause of 1001 (25.7\%) of the surveyed students not attending orientation. orientation. However, almost half (1 604 / 48.5\%) of the surveyed students would like some of the orientation sessions to be offered again later in the year. The outcome of study revealed that $1835(47.3 \%)$ of the students were ignorant of where the Student Development Support (SDS) was located on their campus. Just under 50 per cent $(47.5 \%)$ of the students who participated in the study were unhappy with their living places. The findings further showed that $1187(31.8 \%)$ of the participants encountered difficulties with transport. The majority of the respondents 2827 (74.9\%) would choose University of the Mega Don again if they were re-choosing a University. Most of the surveyed students, 58.3 per cent, valued their experience at University of the Mega Don between good and very good.

Keywords: student experience, academic disciplines, academic integration 


\section{INTRODUCTION}

Guided by previous studies, the current study sought to explore descriptively data related to but not limited to students' total experiences including orientation, social life both on campus and where they live, student support and development, living and transport arrangements. In unpacking this phenomenon, attention was given to (1) first year students' experience at University of the Mega Don (pseudonym) within the first few weeks of their studies, and (2) identify some of the problems they faced.

Consistent with Lowe and Cook's (2003) research, first year students tend to find the changeover from school to university difficult. The low graduation output and high attrition rates in South African universities are a cause for concern. Researchers have argued that not only is lack of understanding of first year experience inadequate to meet students' needs, but also there is a considerable waste of student potential and capacity if not well understood (Lewin and Mawoyo 2014; Thurber and Walton 2012; Scott 2008). Even though the first year is an important transition point, research is inconclusive on ways of cultivating the right frame of mind aimed at enhancing success and persistence in learning at tertiary education and beyond (Scott 2008; Hillman 2005). Additionally, there is not much evidence to support the view that crucial status afforded to students is associated with a positive first year experience (FYE) retention. Therefore, the debate is insufficient on how universities successfully maximise the chances of a smooth changeover from high school through an adoption of extracurricular programmes and support services (Baker 2012; Lourens and Smit 2003).

Following the publication of the national cohort students by Scott (2008), it is possible to assess the efficiency of the higher education (HE) sector based on the performance of the 2000 cohort of entrants. Scott's (2008) findings raised the following points of concern:

- In comparison to those of other countries, HE participation rates in South Africa remains low.

- Approximately 30 per cent of the limited numbers of students who enter the South African HE system annually drop out during their first year of studies (Scott 2008, 9).

Scott's (2008) study suggests that much more scientific enquiry into the difficulties of transition between school and higher education is required. Thus, the present study in part is motivated by Scott's (2008) study. This study thus examines the experience of first year students in their first six months of being university students.

The article is arranged as follows: The preceding part unearths previous literature related 
to the students' FYE. This is followed by the methodology section as well as a separate section on both results and discussion of the study. The article concludes with an implication to understanding students’ FYE at university

\section{LITERATURE REVIEW: FIRST YEAR STUDENT EXPERIENCE IN A UNIVERSITY}

In early 2000, the work of Lourens and Smit (2003, 169-173) on "retention: predicting firstyear success" laments that "predicting retention and student performance is an increasing concern for administrators due to the costly effects associated with non-persistence”. Over 14 years from 2003, establishing the total experience of first year students at university is still a great concern not only nationally but internationally (Lourens and Smit 2003). Parallel to establishing total experience of first year students at universities in south Africa, there is yet another immense task regarding how to identify comprehensive challenges that first year students experience (Geiser and Santelices 2007; Herrera 2006; Drysdale, Ross and Schulz 2001; Kovačić 2010).

Studies spanning from Larkin, Rowan, Garric and Beavis (2016), Geiser and Santelices (2007), Herrera (2006) Drysdale et al. (2001) and Kovačić (2010) are vague on their findings regarding the concerns and challenges of establishing and identifying first year students' experience. These studies are notably related but not limited to:

- Using a Markov student flow model from the USA to investigate the role of pre- and postadmission variables in undergraduate institutional persistence;

- $\quad$ Differentiating predictors of retention using adata-mining approach;

- $\quad$ Mining enrolment data from New Zealand to Predict student success; and

- $\quad$ Retention: predicting first year success from South Africa.

Considering the already existing body of knowledge, wide-ranging factors which have predominately been used in predictive modelling of first year students' analysis are said to differ. Albeit varied, a few which appear in most studies include but not limited to: student's age; province in which students matriculated; aggregate attained in grade 12; Grade 12 English symbol (defined as adequate or inadequate); ethnic group; gender; campus where the student studied (if applicable); mode of study (full time versus part time); financial aid (Yes/No); marital status; type of accommodation (resident student or not), and classification of educational subject matter (CESM) category (i.e. major field of study) (Kovačić 2010; Geiser and Santelices 2007; Lourens and Smit 2003, 171-172). Detailed in their work, ibid.s' results 
suggest that "there seems to be a significant relationship between the number of subjects and the ability to pass in the first year and the dropout of students in the second year” (Lourens and Smit 2003, 174). The authors add that there is "high significant association (Chi square = 210.85, $\mathrm{p}<0.0001$ ) amongst student dropout and the students' success (Lourens and Smit 2003, 174). Even though that is the case, it is unclear how other factors such as family income or parttime employment play a role in first year student experiences. In support of this position, Lourens and Smit $(2003,174)$ recommend that "incorporating non-academic factors ... such as family income or employment status in the analyses would result in more accurate predictions of retention characteristics”.

This study utilised Tinto's (2013) student departure theory to examine the experience of first year students in their first six months as university students. Tinto (1993; 2012) identified “social and academic integration” of first year students as predictors of how they would handle challenges adapting into the culture and expectations of the higher education setting. In brief, Tinto's (1993) model (see Figure 1) was used for explanatory purposes into the reasons individual students may dropout prior to degree completion. Crucial aspect to this theory was used to unpack how students with various pre-conceived attributes adapt into the institution's culture. The theory was used to explore how these interactions impact students' experiences (positively or otherwise) and hence have a bearing on whether they stay or not.

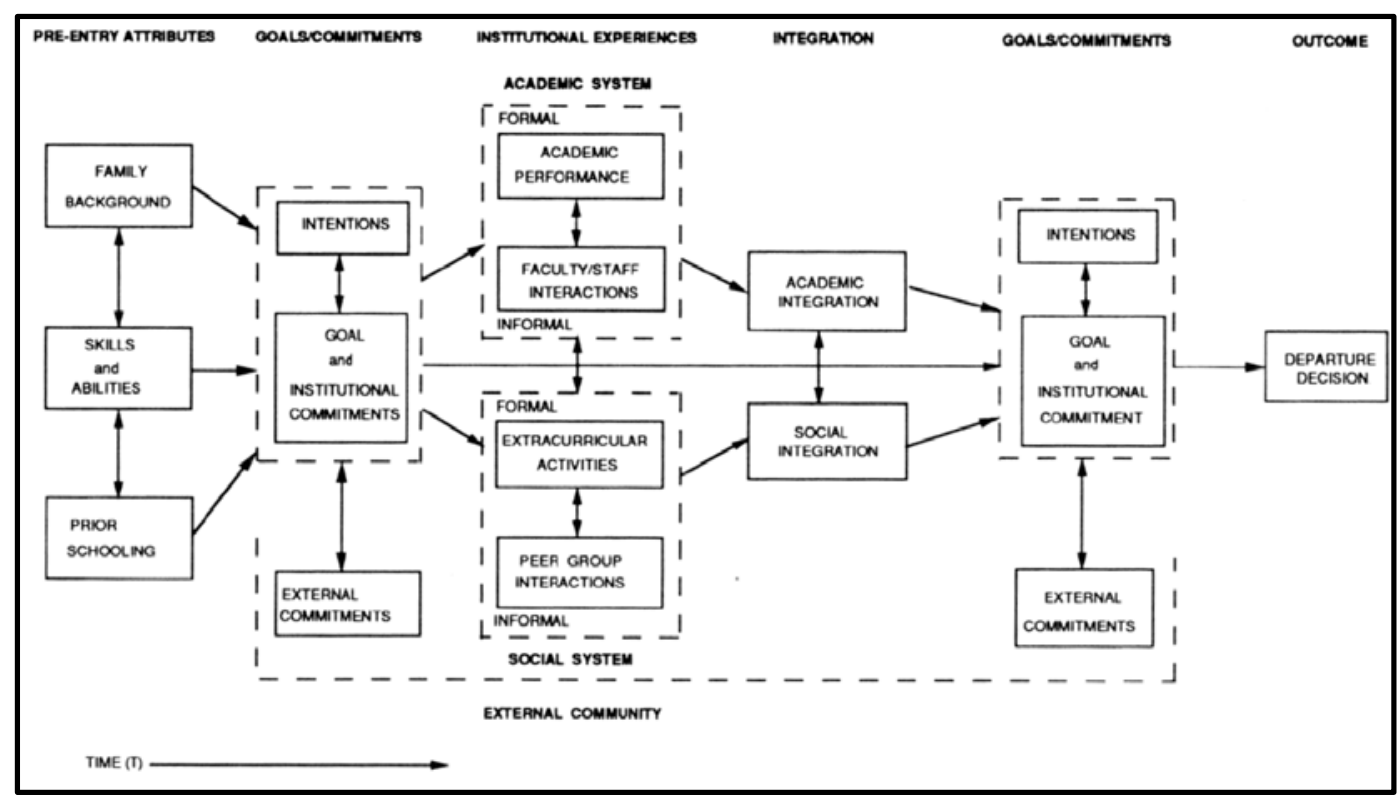

Figure 1: A longitudinal model of institutional departure (Tinto 2013)

\section{Predictability of background, gender and ethnicity on first year student experience}

In predictive modelling of first year students' experience ( $1^{\text {st }}$ YSE), there has been discussions 
related to the type of predictive modelling techniques efficiency (Kotsiantis, Pierrakeas and Pintelas 2004). These predictive modelling techniques range from applying machine learning to Bayesian analysis. Drawing from the research of Kotsiantis et al. $(2004,4)$ on "predicting student success by mining enrolment data", the authors explained they "used key demographic variables and assignment marks in the supervised machine learning algorithms (decision trees, artificial neural networks, naïve Bayes classifier, instance-based learning, logistic regression, and support vector machines) to predict students' performance at the Hellenic Open University”. Their study does not sufficiently establish that background is a good predictor of student experience (Kotsiantis et al. 2004). In support of ibid., evidence points to the fact that "background characteristics are not good predictors of final outcomes because they are just a starting point and there are other factors that may contribute to the difficulties students will have to deal with during his/her study" (Kovačić 2010, 3). Conversely, Yu et al. (2007) suggest that "with the use of classification tree based on an entropy tree-splitting criterion, there seems to [be] supporting evidence that cumulated earned hours was the most important factor contributing to retention” even though gender and ethnic origin are insignificant. With these findings, there is sufficient and inherent indication that demographic factors are yet to be established as having direct correlation with $1^{\text {st }}$ YSE.

\section{Demographics and course environment (programme)}

In the mid-2000s, an investigation conducted by Herrera's (2006) using a Markov student flow model shed light into the role of pre- and post-admission attributes in undergraduate institutional persistence. The findings suggested an unbalanced relation between demographic factors and predicting academic level. In fact, some unclear evidence via a number of analysis techniques such as Nagelkerke's $\mathrm{R}^{2}$ coefficient and the Cox and Snell's $\mathrm{R}^{2}$ coefficient have all been used to establish the relationship between findings and students' demographics and course environment variables (Herrera 2006; Kovačić 2010, 11). However, the consensus reached was that “only $11.2 \%$ of the disparity in study out-come is clarified by students' demographics and course environment variables" (Kovačić 2010, 11). Other analysis related to "student persistence which is unclear suggest[s] that programme level is factors for predicting student persistence" (Kovačić 2010,12). No specific nor candidate reasons have been assigned to these dissimilar and unconfirmed results though pockets of the results show promising relationship between $1^{\text {st }}$ YSE and various factors. 


\section{High school grade, socio-economic and student success}

One study aimed at investigating "validity of high-school grades in predicting student success beyond the freshman year: high-school record vs. standardized tests ...” (Geiser and Santelices 2007, 1). Ibid. suggests that "high-school grade point average (HSGPA) is consistently the best predictor not only of freshman grades in college but the outcome indicator most often employed in predictive-validity studies and four-year college outcomes as well” (Geiser and Santelices 2007, 1). In addition, the authors found that "compared to high-school gradepoint average (HSGPA), scores on standardized admissions tests such as the SAT I are much more closely correlated with students' socioeconomic background characteristics” (Geiser and Santelices 2007, 1).Geiser and Santelices $(2007,1)$ argued that "given these widespread and contrasting perceptions of test scores and grades, it is understandable" that some universities "deemphasise ... standardized tests in favor of HSGPA such that other admissions factors would not cause misgivings among some critics”.

\section{Campus, academic disciplines and pedagogy}

Some have also analyzed groupings of higher-level, such as campuses and academic disciplines, on the predictive validity of student-level criteria. Geiser and Santelices $(2007,1)$ suggest that "because students are clustered within different campuses, academic disciplines and entering freshman cohorts and because their entry into such higher-level groupings may be systematically related to admissions factors - e.g., students admitted at more selective campuses may have higher HSGPAs, on average - it is possible that group-level effects could account in part for the relationships" (Geiser and Santelices 2007, 17). Although this is the case, what is not clear is that "the limits of prediction are especially evident when attempting to predict individual outcomes rather than group outcomes or averages for large samples of students" (Geiser and Santelices 2007, 17). Ibid. laments this is because "predicted outcomes for individual students, based only on factors known at admission are subject to considerable uncertainty and wide error bands” (Geiser and Santelices 2007, 25). A significant trend of reasoning lately is that “... strand of literature encourages university academics working with first year students to reflect carefully upon their pedagogical choices in pursuit of quality learning and teaching environments, particularly in those that contain online learning components” (Larkin et al. 2016, 1-16). A respondent, as reported by Larkin et al. (2016, 116), suggested some courses are “... particularly well structured with the online/face2face components." Although that is the case, some respondents expressed they "... hated the pressure” and added that "... I think week 4 ... we had four things due in the one week, which 
was just like all of us had a breakdown” (Larkin et al. 2016, 1-16). This stems from the fact that recently a study conducted in a South African university regarding "an institutional model for improving student retention and success” found that "the term High Impact Modules (HIMs) was coined to signify such modules' potential impact on performance indicators on the one hand and the strategic intent of the university on the other” (Ogude, Kilfoil and Du Plessis 2012, 21-34). Ogude et al. (2012, 21-34) argue that "high failure and dropout rates undermine (a) sustainability and (b) excellence." The authors explain that "HIMs are thus characterised as modules: (i) with large enrolment numbers (>200); (ii) that cater for a number of programs across faculties; (iii) are associated with academic programs of national significance; (iv) have high dropout rates (>10\%); and (iv) high failure rates (>30\%)” (Ogude et al. 2012, 21-34).

Albeit not fully exploited, an attempt has been made to understand "Cognitive learning styles and academic performance in 19 first year university courses: Successful students versus students at risk”. In response to the attempt, Drysdale et al. (2001, 270-76) found that “...students experiencing academic difficulty (GPAs $\leq 2.00)$ are 6.5 times more likely to drop out than students experiencing academic success (GPAs > 2.00)”. Ibid. add that “... students with cumulative GPAs below or equal to 2.0 after their 1st year were more likely to withdraw than students with GPAs higher than 2.0 for their 1st year, P2 $=321.88(1), \mathrm{p}<.00001$ " (Drysdale et al. 2001, 270-76). Some observations investigating how construct systems of first year university students have changed also noticed “... a significant rise in self-esteem (SID), $\mathrm{t}(27)=-.55, \mathrm{p}<.05, \mathrm{r}=.25$ (a medium effect size)" (Ribeiro et al. 2012, 170-180). When testing for the unique contribution regarding presence of dilemmas after controlling for psychological symptoms at assessment, ibid. found that “... the overall model was significant, $\mathrm{F}(2,25)=10.04 ; \mathrm{p}=.001$, explaining $40 \%$ of the variance, but presence of dilemmas at the beginning of the year $(\beta=.14, p>.05)$ added only $1.9 \%$ to the variance explained by psychological symptoms at Assessment $1(\beta=.65, \mathrm{p}=.000)$ " (Ribeiro et al. 2012, 170-180).

What these variations in findings suggest about experience of first year students and problems they face is that they are inconclusive. Not only are they unsettling, there has not been acceptable trends or phenomena observed firmly in current South African universities. For this reason, the current study sought to explore the objectives as stipulated below.

\section{Objectives of the study}

- To establish the experience of first year students within the first few weeks of their studies;

- To identify some of the problems that the first year students experience within the first few 
weeks of their study.

\section{METHODOLOGY}

This study is a descriptive analysis of first year students' experience at a university in South Africa commencing their various fields of study (Creswell 2014). Based on the research objectives, a questionnaire was used as the data collection tool. This was filled out by all first year students on the completion of their first six weeks. Thus, all first year students studying at University of the Grand Don for the first time were surveyed in order for it to be all-inclusive. Data was collected using a one-page paper-based questionnaire following the research objectives to survey and obtain information on first year students' experience. The questionnaire was an adopted version from the University of Johannesburg (UJ) (University of Johannesburg 2013). The questionnaire (cf. Appendix: Questionnaire) which was mainly comprised of tick boxes and extended answer questions on students' total experience thus far including orientation, social life both on campus and where they live, student support and development, living and transport arrangements. There were demographic as well as explanatory questions relating to the different aspects of the first year experience. Students were urged to write their student numbers on the questionnaires to allow for individualised follow-up and support where necessary. The survey is therefore not anonymous but the students' protection was assured by not contravening ethical standards of the university (cf. Ethical certificate - names and words that identify with the university have been blinded). Because this is a descriptive study, data was analysed using descriptive statistics.

\section{RESULTS AND DISCUSSION}

Guided by the research (cf. Research objectives), the present study aimed at addressing students' experience including orientation, social life both on campus and where they live, student support and development, living and transport arrangements. Most surveyed respondents (3 611 out of 3846 (93.9\%)) indicated that they were registered for the first time at University of the Mega Don, while only 235 (6.1\%) had already been in a foundation programme at University of the Mega Don. As noted by previous researchers, various reasons account for choice of campus, some of which include online facilities and teaching and learning (Yu et al. 2007; Kovačić 2010, 11). However, in this particular case, the dominate reason has been due to the choice of programme. Tinto (1998) suggests that this interaction leads to positive (integrative) experiences that enhances their commitment to the institution. This is particularly true as Yu et al. (2007) argue that these factors are yet to be established as having 
direct correlation with $1^{\text {st }}$ YSE. Figure 2 is a representation of the number of campuses that took part in the survey. The majority of participants were enrolled in Pretoria Campus (1 463 out of 3932 (37\%)), followed by Soshanguve South Campus (593 out of 3932 (15\%)) and GaRankuwa Campus (488 out of 3932 (12\%)). On the contrary, Polokwane Campus had the lowest participants (150 out of 3932 (4\%)). The following section illustrates their responses over an array of variables. One thing that can be said here is that the results are inconclusive regarding previous literature (Yu et al. 2007).

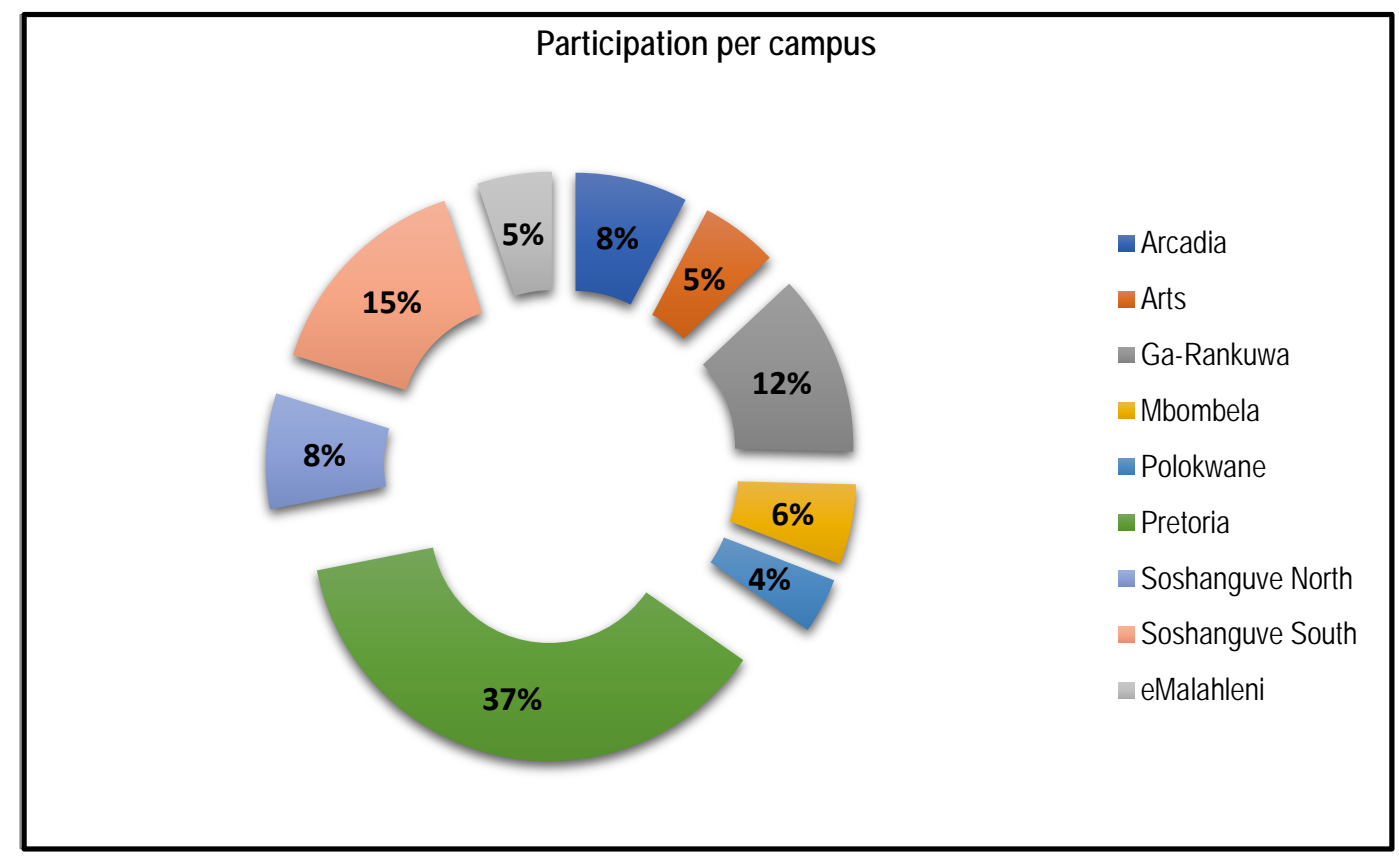

Figure 2: Participation per campus $(n=3932)$

A response rate of 27 per cent (4 020 out of 15 217) of this total of target participants was achieved in the study. The ratio in the study in terms of gender leaned slightly in favour of the females. One thousand nine hundred and ninety-six (1 996) out of 3913 females participated in the survey as opposed to 1917 males representing 51 percent females and 49 percent males. In addition, the trend of participants in the study in terms of age indicated that the majority (3 $283(83.7 \%)$ ) were between the ages of 18 and 21. With regards to disability, findings reveal that 34 (0.9\%) of the surveyed students have disabilities. However, all most all (327 out of 338 (96.7\%)) of these students did not register with the disability office. Previous researchers such as Lourens and Smit (2003) and Herrera (2006) have observed there is "high significant association (Chi square $=210.85, \mathrm{p}<0.0001$ ) between student dropout and the success of students.” However, in this study, there is no indication of such phenomenon.

Over 50 per cent of students, especially those from financially struggling backgrounds, dropout due to inability to carry the direct and indirect costs of university study or are unable 
to continue studying when the financial burden increases. This result matches with previous studies (Lourens and Smit 2003). Ibid. previously pointed out that there is a good relation between drop out and low-income or disadvantaged backgrounds. The findings are not so far from another phenomenon related to finance. Consistent with previous research, the current results indicate that most of the first year students (1 736 (47.1\%)) are financed by the National Student Financial Aid Scheme (NSFAS) (Herrera 2006). This is what researchers such as Larkin et al. (2016) described as being in a case of quality learning and teaching settings. Undoubtedly, the NSFAS plays an important role in increasing access to higher education for underpreviledged students. Government funds to NSFAS amounted to R5.769 billion, in 2013/14. R3.693 billion of the entire portion was for loans and bursaries to universities (Van Zyl, Gravett and De Bruin 2012). Larkin et al. (2016) have also drawn attention to increased amount of work first year student encounter. In their previous research the authors argued that some respondents indicated that they “... hated the pressure” and added that “... I think week 4 ... we had four things due in the one week, which was just like all of us had a breakdown" (Larkin et al. 2016, 1-16).

The results of this study can be likened to their work (Larkin et al. 2016, 1-16) in that the current findings indicate that 1001 (25.7\%) of the students who took part in the survey did not attend orientation as a result of late registration as well as other reasons. But, 1604 (48.5\%) of the surveyed students would welcome some orientation type sessions to be reoffered later in the year. Findings reveal that more or less than 1772 (46\%) students reported studying for less than 10 hours per week disregarding official class times. The students' assertion has been echoed in the work of Geiser and Santelices (2007, 17). Findings further revealed that 2876 (74.3\%) of all participants mentioned that they were anxious about their term/semester tests. Many respondents (87\%) reported that they knew what the lecturers expected of them. Only 40 per cent had not yet spoken to any of the lecturers, which was strongly acknowledged by Ribeiro et al. (2012).

Following the findings, the researchers suggest that in such scenarios, the university should create a first-year coordinator position/unit (Baker 2012). They should also establish a first-year team whose principal responsibilities will be to enhance and promote efforts that continually improve a university-wide, first-year experience (Baker 2012). Various commentators have indicated the difficulty regarding social aspects of $1^{\text {st }}$ YSE (Baker 2012; Yu et al. 2007). Just as the work of Yu et al. (2007) the current results show that 1835 (47.3\%) of the students were ignorant of where the SDS was located on their campus, and majority (3 247 (83\%)) had not utilised the services provided by the Student Development and Support 
(SDS). Looking at participation in sports, the survey results indicate that 3107 (80.9) had not yet attended or participated in any sporting events at University of the Mega Don, and approximately 90 per cent (3 107) had not joined any clubs or associations. This is a matter of concern as the majority is still very young (18-21 years of age) and need to be active in sporting and social activities. Only 1121 (29\%) of surveyed students reside in university residences while studying, with 636 (16.5\%) on campus. Almost half of the respondents indicated that they (47.5\%) are not happy with where they live.

Orientation is very important as the students need to know where to go for assistance and they should gain general information about how the university works, thereby improving their chances of success. Ogude et al. (2012, 21-34) characterised this approach as HIMs, which they argue is strongly linked with "high failure and dropout rates" and thus weaken (a) sustainability and (b) quality. Modules: (i) with large enrolment numbers (>200); (ii) that are offered to a number of programs across faculties; (iii) are related with academic programs of national significance; (iv) have high attrition rates (>10\%); and (iv) high failure rates (>30\%) are typical characteristics of HIMs (Ogude et al. 2012, 21-34). Researchers have advanced the point that an attempt to expose new students to the campus facilities and location of different departments is important (Bowden 2013; Baker 2012; Ogude et al. 2012). All campuses should publicise the location of offices such as SDS and students should be encouraged to use these facilities (Bowden 2013; Baker 2012). It is also suggested that offices such as SDS must be improved so that they provide academic support services for all first year students and not just those at risk of failing (Bowden 2013; Baker 2012). These can include services such as writing centres, mathematics labs, tutoring, technology-support, counselling, and support services for students with learning disabilities. In addition, the university must emphasise to students with disabilities the importance of registering with the disability office (Bowden 2013; Baker 2012). This is important as they will receive specialized support, if needed, thereby enhancing their chances of success. It is also argued that there is the need for course-based orientation tours and treasure hunts to introduce students to the university environment (Bowden 2013; Baker 2012). Thus, the University should introduce a mid-year orientation programme to reacquaint students with the institution's services and requirements with alternative formats to address the range of student needs and to cater for late registrations (Bowden 2013).

The first year of university is a critical one in which students are likely to develop lasting viewpoints, morals and designs of behaviour in relation to higher education and lifelong learning. It is in this year that institutions of higher learning either retain or lose the students; it is therefore crucial for first years to have a worthwhile and positive experience. Upcraft and 
Kramer $(1995,18)$ extended this theory, stating that "the greater the quantity and quality of involvement, the more likely the student will succeed in college”. The view is that higher education staff can assist students become active in various ways (Upcraft and Kramer 1995). This includes two successful orientation activities at the beginning of the year that familiarize students with different campus organizations, and scheduling first year planning conferences between students and their advisors (Upcraft and Kramer 1995).

As alluded by Herrera (2006), the findings of this study show that 1187 (31.8\%) of the surveyed students have transport problems. With regards to type of transport used to get to campus, the survey results indicate that over 60 per cent of the surveyed students use buses and taxis to get to campus. In general, observers have reflected on the fact that overall satisfaction can be difficult to achieve (Herrera 2006; Upcraft and Kramer 1995). In this instance, majority of the respondents 2827 (74.9\%) would choose University of the Mega Don if they were rechoosing a higher education institution. The results of the survey indicate that most surveyed students, 58.3 per cent, rated their experience at University of the Mega Don between good and very good.

There is an indication that FYIES study has made good progress in enhancing transition to university and improving the experience quality for first year students at the University of the Mega Don. The concentration of efforts geared towards high quality transition programmes as well as checking and reacting to the needs and experiences of first year students may yield returns.

Social integration of fist year students at University of the Mega Don is important to increase the students' level of social integration as well as increases their level of academic integration. Sporting facilities, activities, associations and clubs should be publicized widely to first years and they should be encouraged to participate. This is crucial given the age group of first year students which mainly ranges between 18 and 21 years, and should help to keep them active and engaged. This in turn will have a positive impact on the success of their studies. Authors in previous studies found that “... the overall model was significant, $F(2,25)=10.04$; $\mathrm{p}=.001$, explaining 40 per cent of the variance, but presence of dilemma sat the beginning of the year $(\beta=.14, p>.05)$ added only 1.9 per cent to the variance explained by psychological symptoms at Assessment $1(\beta=.65, \mathrm{p}=.000)$ ” (Ribeiro et al. 2012, 170-180).

The University should provide mechanisms to address the financial needs of needy students at the first year undergraduate level while reducing the burden on the NSFAS. With regards to accommodation and transport, it is recommended that a follow-up qualitative study (more in-depth interviews) could be conducted to see exactly what the issues are. This will help 
shed light into exactly what kind of intervention is needed. The University should send first year students targeted messages, through a variety of communication tools, to ensure that they receive essential information. Such communication would create greater awareness of the resources that are available to support students throughout their first year.

\section{SUMMARY}

\section{The profile of the students}

A response rate of 27 per cent (4 020 out of 15 217) of the target participants was achieved in the study. The gender ratio in the study slightly leaned in favour of the females. A total of 1996 out of 3913 females responded to the survey questionnaire and 1917 males responded, representing 51 per cent females and 49 per cent males. In addition, the trend of participants in the study in terms of age indicated that the majority (3 283 (83.7\%)) were between the ages of 18 and 21. With regards to disability, the survey results indicate that $34(0.9 \%)$ of the surveyed students have disabilities. However, the majority (327 out of 338 (96.7\%)) are not registered with the disability office.

\section{Financial assistance}

More than half of students, especially those from low-income or disadvantaged backgrounds, dropout because they are unable to bear the direct and indirect costs of university attendance or are unable to continue attending when financial needs change. The results of the survey indicate that most of the first year students (1 736 (47.1\%)) are financed by the NSFAS. There is no doubt as to the importance of the NSFAS in increasing access to higher education for poor students. In 2013/14, government funds to NSFAS amounted to R5.769 billion, of which R3.693 billion was for loans and bursaries to universities (Ministry of Higher Education and Training 2013).

\section{Academic integration}

The results indicated that 1001 (25.7\%) of the surveyed students did not attend orientation due to late registration and other reasons. However, 1604 (48.5\%) of the surveyed students would like some orientation type activities to be repeated later in the year. Data shows that approximately 1772 (46\%) students reported that they study for less than 10 hours per week outside of lecture times. The majority of (70\%) do not miss any classes/labs/practicals in a 
normal week. The findings of this study show that 2876 (74.3\%) of all surveyed students stated that they were worried about their term/semester tests. Many respondents (87\%)stated that they knew what the lecturers expected of them. Only 40 per cent had not yet spoken to any of the lecturers.

\section{Social integration}

The findings of this study show that 1835 (47.3\%) of the students did not know where the SDS was located on their campus, and majority (3 247 (83\%)) had not utilised the services provided by the SDS. With regards to sports participation, the survey results indicate that 3107 (80.9) the surveyed students had not yet attended or participated in any sporting events at University of the Mega Don and approximately 90 per cent (3 107) had not joined any clubs or associations. This is a matter of concern as the majority is still very young (18-21 years of age) and need to be active in sporting and social activities.

\section{Accommodation}

Only 1121 (29\%) of surveyed students reside in university residences while studying, with 636 (16.5\%) on campus. Almost half (47.5\%) of the respondents indicated that they are not happy with where they live.

\section{Transport}

The findings of this study show that 1187 (31.8\%) of the surveyed students have transport problems. With regards to type of the transport used to get to campus the survey results indicate that over 60 per cent of the surveyed students use buses and taxis to get to campus.

\section{Overall satisfaction}

The majority of the surveyed students (2 827 (74.9\%)) would choose University of the Mega Don if they were rechoosing a higher education institution. The survey results indicate that most students, 58.3 per cent, rated their experience at University of the Mega Don between good and very good.

\section{Implications}

The implications of the study include that faculty staff members should undertake professional development courses in order to ensure that they understand and are aware of the unique needs of first year students. Further, students should be encouraged to talk to their lecturers and tutors/mentors. This should improve their chances of success, as they will receive information 
about a range of issues and feel more open with their lecturers and mentors. Keeling (2003) notes that students often have lofty goals and high expectations, but often lack realistic plans for achieving their goals. More importantly, separate interventions may be needed to encourage students to study more hours outside class to avoid pressure towards tests and exam times. Additionally, the following interventions could be implemented:

- Small group teaching in tutorials;

- $\quad$ Group assessment strategies; and

- $\quad$ Develop peer-mentoring programmes to assist first year students’ transition into university life.

\section{ACKNOWLEDGEMENT}

The researchers wish to extend their heartfelt gratitude to the following people without whom the First-Year Initial Experience Survey (FYIE) would not have been successful:

- Institutional Research in the Directorate of Quality Promotion (DQP) - University of Mega Don

- Dr. D. Naidoo - Executive Director

- Dr. S Caroline - Director.

\section{REFERENCES}

Baker, S. 2012. Students' writing and the transitions from school to university: Hybrid "discourse of writing" positions of students and teachers. 1st International Australasian Conference on Enabling Access to Higher Education, Adelaide, Australia.

Bowden, J. L. H. 2013.What's in a relationship? Asia Pacific Journal of Marketing and Logistics 25(3): 428-451.

Creswell, J. W. 2014. Research design: Qualitative and quantitative and mixed method approach. $4^{\text {th }}$ Edition. Sage Publication Ltd.

Drysdale, M. T. B., R. Ross and R. A. Schulz. 2001. Cognitive learning styles and academic performance in 19 first-year university courses: Successful students versus students at risk. Journal of Education for Students Placed at Risk (JESPAR) 6(3): 271-289.

Geiser, S. and M. V. Santelices. 2007. Validity of high-school grades in predicting student success beyond the freshman year: High-school record vs. standardized tests as indicators of four-year college outcomes. Research and Occasional Paper Series: CSHE.6.07. University of California, Berkeley. http://cshe.berkeley.edu (Accessed 20 February 2017).

Herrera, O. L. 2006. Investigation of the role of pre- and post-admission variables in undergraduate institutional persistence, using a Markov student flow model. PhD Dissertation, North Carolina State University, USA).

Hillman, K. 2005. The first year experience: The transition from secondary school to university and TAFE in Australia. LSAY Research Reports. Longitudinal surveys of Australian youth research report. 
Keeling, S. 2003. Advising the millennial generation. NACADA Journal 23(1\&2): 30-36. http://www.nacada.ksu.edu/Resources/Clearinghouse/View-Articles/Academicallyunder prepared-students.aspx\#sthash.v5RlpHv4.dpuf

Kotsiantis, S., C. Pierrakeas and P. Pintelas. 2004. Predicting students' performance in distance learning using machine learning techniques. Applied Artificial Intelligence 18: 411-426

Kovačić, Z. J. 2010, Early prediction of student success: Mining students' enrolment data. In Proceedings of Informing Science \& IT Education Conference (InSITE) 2010. Open Polytechnic, Wellington, New Zealand.

Larkin, K., L. Rowan, B. Garric and C. Beavis. 2016. Student perspectives on first year experience initiatives designed for pre-service teachers in their first weeks of university study. Journal of University Teaching \& Learning Practice 13(1): 1-16.

Lewin, T. and M. Mawoyo. 2014. Student access and success: Issues and interventions in South African Universities. Inyathelo: The South African Institute for Advancement.

Lourens, A. and I. P. J. Smit. 2003. Retention: Predicting first-year success. SAJHE/SATHO 17(2): 169176.

Lowe, H. and A. Cook. 2003. Mind the gap: Are students prepared for higher education? Journal of Further and Higher Education 2(1): 53-76.

Ogude, N., W. Kilfoil and G. du Plessis. 2012. An institutional model for improving student retention and success at the University of Pretoria. The International Journal of the First Year in Higher Education 3(1): 21-34.

Ribeiro, E., G. Feixas, A. Maia, J. Senra and G. Dada. 2012. Changes in the construct systems of firstyear university students: Impact on psychological symptoms and problem-solving skills. Journal of Constructivist Psychology 25(2): 170-180.

Scott, I. 2008. First-year experience conference. Stellenbosch, September 2008.

Thurber, C. and E. Walton. 2012. Homesickness and adjustment in university students. Journal of American College Health 60(5): 415-419.

Tinto, V. 1993. Leaving college: Rethinking the causes and cures of student attrition. $2^{\text {nd }}$ Edition. Chicago: University of Chicago Press.

Tinto, V. 1998. College as communities: Taking the research on student persistence seriously. Review of Higher Education 21: 167-178.

Tinto, V. 2012. Enhancing student success: Taking the classroom success seriously. The International Journal of the First Year in Higher Education 3(1): 1-8. 10.5204/intjfyhe.v2i1.119 (Accessed 22 May 2013).

Tinto, V. 2013. Theoretical underpinnings and research framework for student success. Presentation to the CHE symposium 20 August 2013, Pretoria. http://www.che.ac.za/content/regional-symposiastudentsuccess-19-23-august-2013 (Accessed 15 January 2014).

University of Johannesburg. 2013. UJ enrolment details. https://mis.uj.ac.za/heda/fsmain.htm (Accessed 9 June 2013).

Upcraft, M. L. and G. Kramer. (Eds.). 1995. First-year academic advising: Patterns in the present, pathways to the future (Monograph No. 18). Columbia, SC: University of South Carolina, National Resource Center for the Freshman Year Experience.

Van Zyl, A., S. Gravett and G. P. de Bruin. 2012. To what extent do pre-entry attributes predict first year student academic performance in the South African context? South African Journal of Higher Education 26(5): 1095-1111.

Yu, C. H., S. DiGangi, A. Jannasch-Pennell, W. Lo and C. Kaprolet. 2007. A data-mining approach to differentiate predictors of retention. In the Proceedings of the Educause Southwest Conference, Austin, Texas, USA. 


\section{APPENDIX}

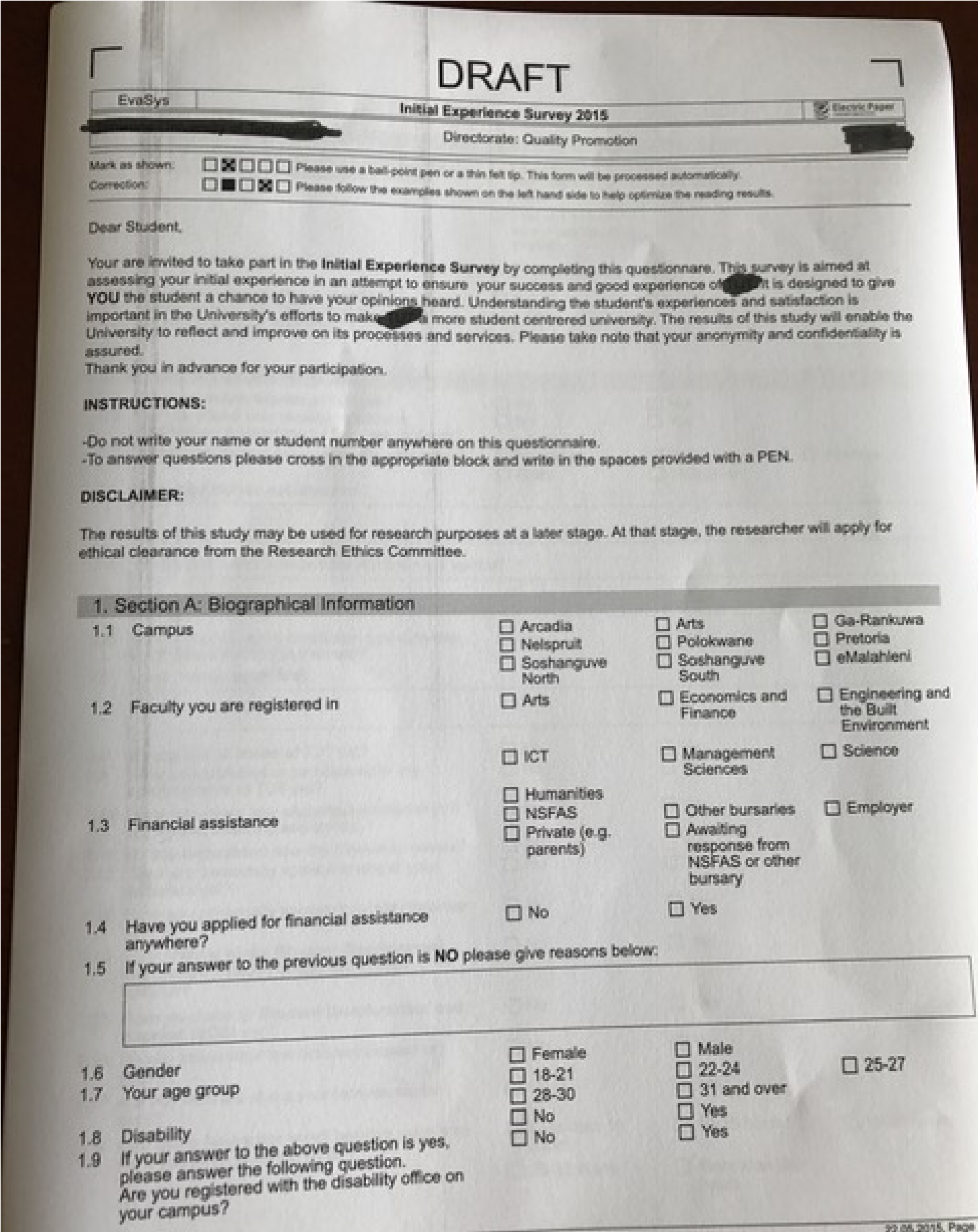




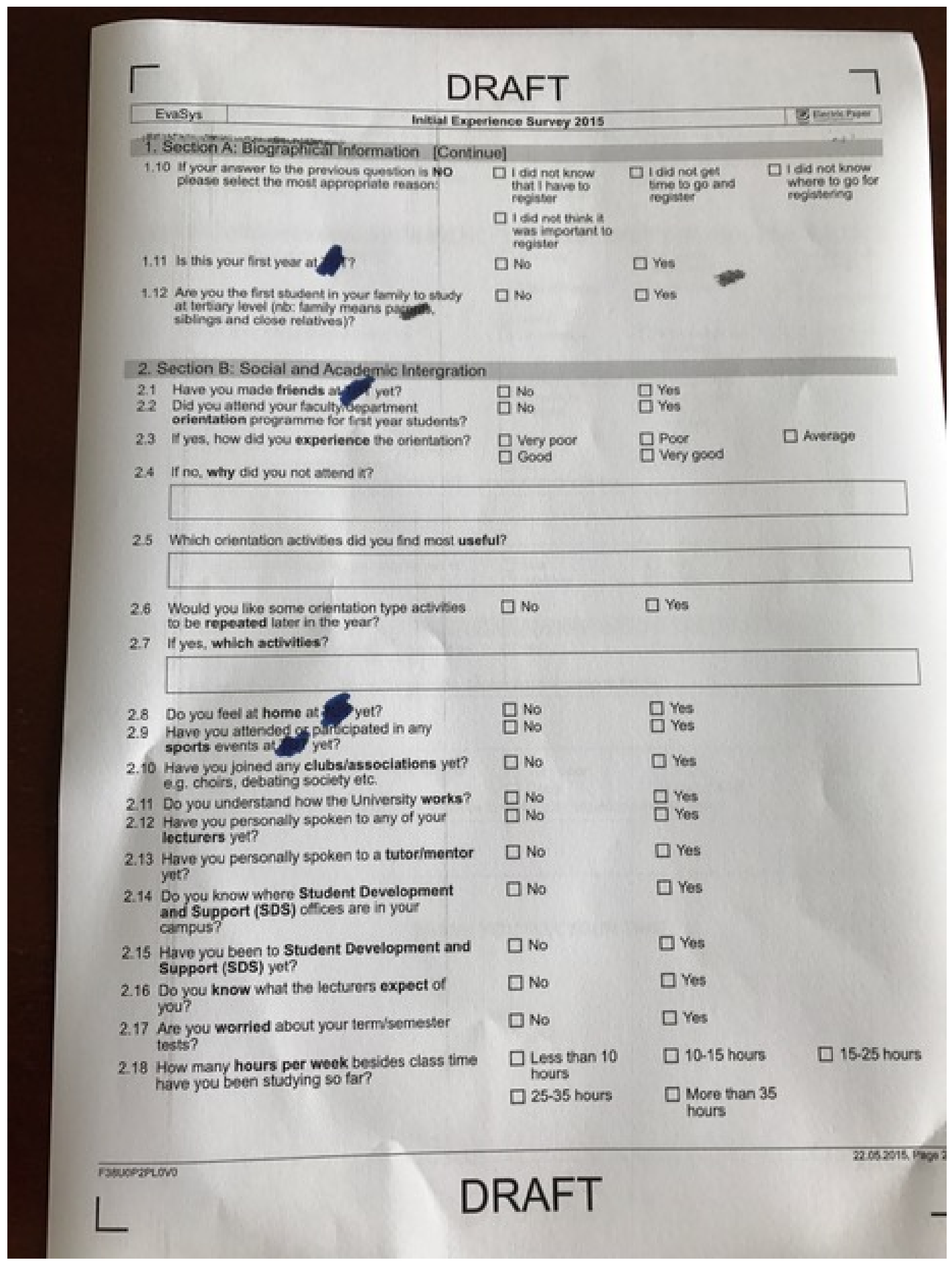




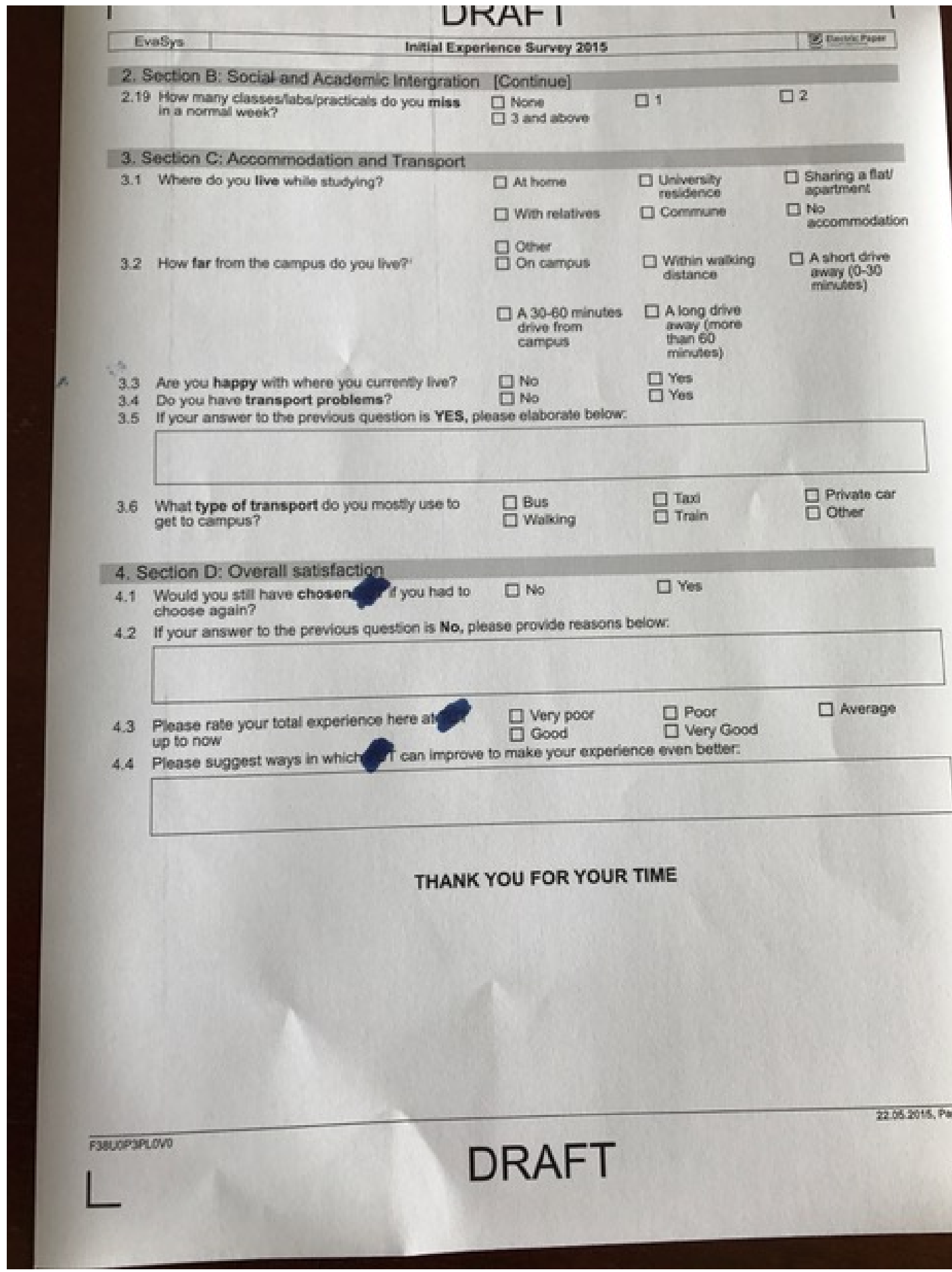

